\title{
Determinants of Chief Executive Officer Compensation: Some Recent Evidence For The Retail Sales and Foods Industries
}

\author{
Dr. W. Ken Farr, Economics, Georgia College \\ Dr. Joseph C. Samprone, Jr., Economics, Georgia College
}

\begin{abstract}
This study examines factors which influence compensation of chief executive officers (CEOs) in the retail sales and foods industries. Because many of the factors which potentially influence compensation are correlated with one another, multicollinearity becomes a problem in regression analysis. To avoid this problem, principal component analysis is employed. Specifically, the relationship of firm performance, firm size, and CEO tenure, all measured as a composite of factors, are studied to determine their influence on CEO compensation. In addition, specific industries are studied in isolation and then in combination to examine the effect of pooling data across industries.
\end{abstract}

\section{Introduction}

At the heart of the theory of the firm is the supposition that business behavior is guided by profit maximization. In the neoclassical framework, the assumption is that firms try to increase profits by either increasing revenues, reducing average costs of production, or some combination of the two. Lewellen and Huntsman (1970, p. 710) state that "if it should turn out that profit related goals are consistently subordinated, the relevance of much of our received economic doctrine would become suspect." Given this assumption, it then follows that the responsibility of the chief executive officer (CEO) must be to guide the firm's actions so as to maximize returns to the firm. Based on this idea, if a CEO is successful at increasing returns to the firm then his or her remuneration should reflect this, and visa versa. Firms, therefore, attempt to structure incentive plans which are based on firm performance indicators over which managers have control; for example, various performance measures such as earnings per share, return on assets, and return on stockholder's equity.

On the other hand, since most CEOs of large corporations are relatively minor stockholders, it may be difficult for stockholders in general to compel profit maximizing behavior by managers. According to many economists, a goal other than profit maximization may be the primary one. For example, John Kenneth Galbraith (1971) asserts that CEOs pursue goals of stable sales growth. In addition, Masson (1971) set forth that firms must pay executives some amount within a bargaining range which is related to, and correlated with, marginal revenue product. He further suggests that larger firms will, ceteris paribus, have a higher marginal revenue product of CEO talent than smaller firms. Therefore, size of operations is also considered an important element in analyzing determinants of CEO compensation.

Past studies on the determinants of executive compensation have focused on finding one definitive explanation, most of which centered around the debate between size and profitability. Baumol (1967) stressed that executive salaries appear to be far more closely correlated with the size of operations of a firm than with profitabil- 
The Journal of Applied Business Research - Vol. 6, No. 1

ity. McGuire, et al (1962) and Roberts (1956) found evidence to support this hypothesis while Lewellen and Huntsman (1970) and Masson (1971) found that profits appeared to influence executive compensation more than size. The apparent contradiction between these studies is postulated to be due largely to econometric difficulties; multicollinearity, heteroscedasticity, and errors in variables. Various attempts to deal with these problems have been discussed in the literature with no decisive conclusions being reached (e.g., Baker, Ciscel, and, Dunlevey).

Additional research has extended the original focus to include factors other than size and profitability. For example, a study by Hogan and McPheters (1980) included factors to represent personal characteristics. They stressed that variables such as sales and/or profits should properly measure the efficiency gains of an individual which are given by age, years with a firm, years as CEO, type of administrative background, and level of formal education. They hypothesized that the significance of these factors would be reflective of background characteristics which are independent of performance. And since they found these variables to be significant, they concluded that in addition to a firm's performance and size, personal characteristics which are independent of their influence on performance also influence CEO compensation.

The present study is an attempt to deal with the problems which were encountered by previous researchers. Specifically, this study differs from its predecessors in two fundamental ways. First, it attempts to determine important factors which explain variations in compensation to a firm's CEO in terms of three composite characteristic indices constructed using principal component analysis rather than by using a single variable or a plethora of individual variables representing each characteristic. The indices included in the study are firm performance, firm size, and chief executive officer tenure (the variables included in each characteristic index are defined in the next section). The principal component technique is employed since it creates mutually orthogonal variables which are linear combinations of the original variables (1). This enables the expression of the integrated effects of " $\mathrm{m}$ " variables in a space of dimension less than " $m$ ". That is, a majority of the variability of the original variables can be captured using only a subset of the linear functions (principal components) of the m-dimensional vector. The approach is beneficial in regression analysis for two reasons; first it eliminates multicollinearity and second, it increases the number of degrees of freedom (2). The principal drawback of this method in regression analysis is in the interpretation of statistical results. However, it is possible to determine whether or not the dependent variable (compensation) is influenced significantly by any (or all) of the principal components which are included in the model. The focus is, therefore, one of causal effect.

A second difference in this study is that previous research has not been industry specific (3). As a consequence, past studies have implicitly assumed that compensation is independent of industry and, further, that the effect of a particular firm characteristic is homogeneous across industries. By investigating two industries separately, this study is able to test whether interindustry differences exist in the relationship between compensation and relevant influential characteristics. To accomplish this task, two industries (the retail sales and foods industries) were selected at random, one from the "Fortune Directory of the Fifty largest Commercial-Banking Companies, Life Insurance Companies, Diversified-Financial Companies, Retailing Companies, Transportation Companies, and Utilities," and one from the "Fortune Directory of the Largest U.S. Industrial Corporations (4)."

\section{Variable Definition}

The variables included in each index are defined as follows:

\section{CEO compensation (Comp):}

The elaboration of various authors as to the appropriate measure of compensation has been well documented in other studies (Agarwal, Ciscel, Ciscel and Carrol, Hogan and McPheters, and Lewellen and Huntsman). Executive compensation is defined here as salary plus bonus which includes all salary and bonus payments in 1985, whether paid in cash or deferred, as well as directors' fees and commissions (5). The reason the above selection was made, rather than a more comprehensive measure, was because Lewellen and Huntsman (1970) have shown that little efficiency gains could be made by expand- 
The Journal of Applied Business Research - Vol. 6, No. 1

ing the measure to include items such as pension plan contributions, stock options, or stock appreciation rights. The addition of such items only introduces "noise" (p. 718) into the measurement, therefore, the more narrow definition of compensation was used.

\section{Firm performance index (Fper):}

The variables included in the firm performance index were based on a recent survey conducted by Sibson and Company, Inc., which was presented in the Journal of Accounting (1986). These variables were considered to be important indicators of a firm's performance by those responsible for setting CEO remuneration. The relative short term bias of the following measurements is due to the fact that executive compensation plans tend to link incentive pay to short-term operating results (Financial Executive, May, 1983, and Fortune, May 4, 1981). The firm performance index included the following variables: profit margin in 1985, change in profit margin between 1984 and 1985, return on assets in 1985, change in return on assets between 1984 and 1985, return on stockholder equity in 1985, change in return on stockholder equity between 1984 and 1985, earnings per share in 1985 and the percentage change in earnings per share between 1984 and 1985.

\section{Size index (Size):}

Since it was not obvious which variables best measure firm size, an index was developed from the following: sales in 1985, assets in 1985, and the number of employees in 1985.

\section{Tenure index (Ten);}

The final index employed in this study is a tenure index which is included to measure the influence of CEO background characteristics on compensation as indicated by Hogan and MhPheters (1980). The tenure index includes the following variables: number of years with the firm as of 1985, number of years as the CEO of the firm as of 1985, and the CEO's age as of 1985.

The percent of the total variance which is accounted for by each of the principal components in each index and associated eigenvalues are presented in table 1 for both samples.

\section{Results: Specific Industries}

In regression analysis that employs principal components, the question arises as to which of the components to use as explanatory variables. In this study, this question is answered following the eigenvalue greater than one rule (Kim and Mueller). Only those principal components with eigenvalues greater than one are included in the analysis (table 1). Kim and Mueller (1978, p. 43) point out that "this simple criterion seems to work well, in the sense that it generally gives results consistent with researcher's expectations and when applied to samples from artificially created population models."

Given the significant principal components of the characteristic indices, regressions are applied to the following model:

Comp $=\alpha+\beta$ Fper $+\theta$ Size $+\delta$ Ten $+\mathrm{e}$

Where:

Comp $=$ salary plus bonus (in dollars) of the chief executive officer in 1985.

Fper $=$ an index of variables representative of firm performance in 1985.

Size $=$ an index of variables representative of firm size in 1985 .

Ten $=$ an index of variables representative of the tenure of the chief executive officer of the firm in 1985.

$\mathrm{e}=\quad$ error term.

The principal components selected for inclusion for both the retail sales and foods industries were the same: the first principal component for the size and tenure indices and the first and second principal components for the performance index. While principal component analysis circumvented the multicollinearity problem associated with the raw data, the use of ordinary least squares at this point was found to be inappropriate since heteroscedasticity was detected in both industries using a Breush-Pagan test. This occurred despite attempts to analyze determinants of CEO compensation within specific industries. The heterscedasticity problem centered on the firm performance variables included in the analysis for both industries. Generalized least squares was employed to correct for heterscedasticity and the results are shown in tables 2 and 3 .

A priori, it was expected that a positive rela- 
The Journal of Applied Business Research - Vol. 6, No. 1

Table 1: Cumulative Proportion of Variance Explained by Each of the Principal Components and Associated Eigenvalues

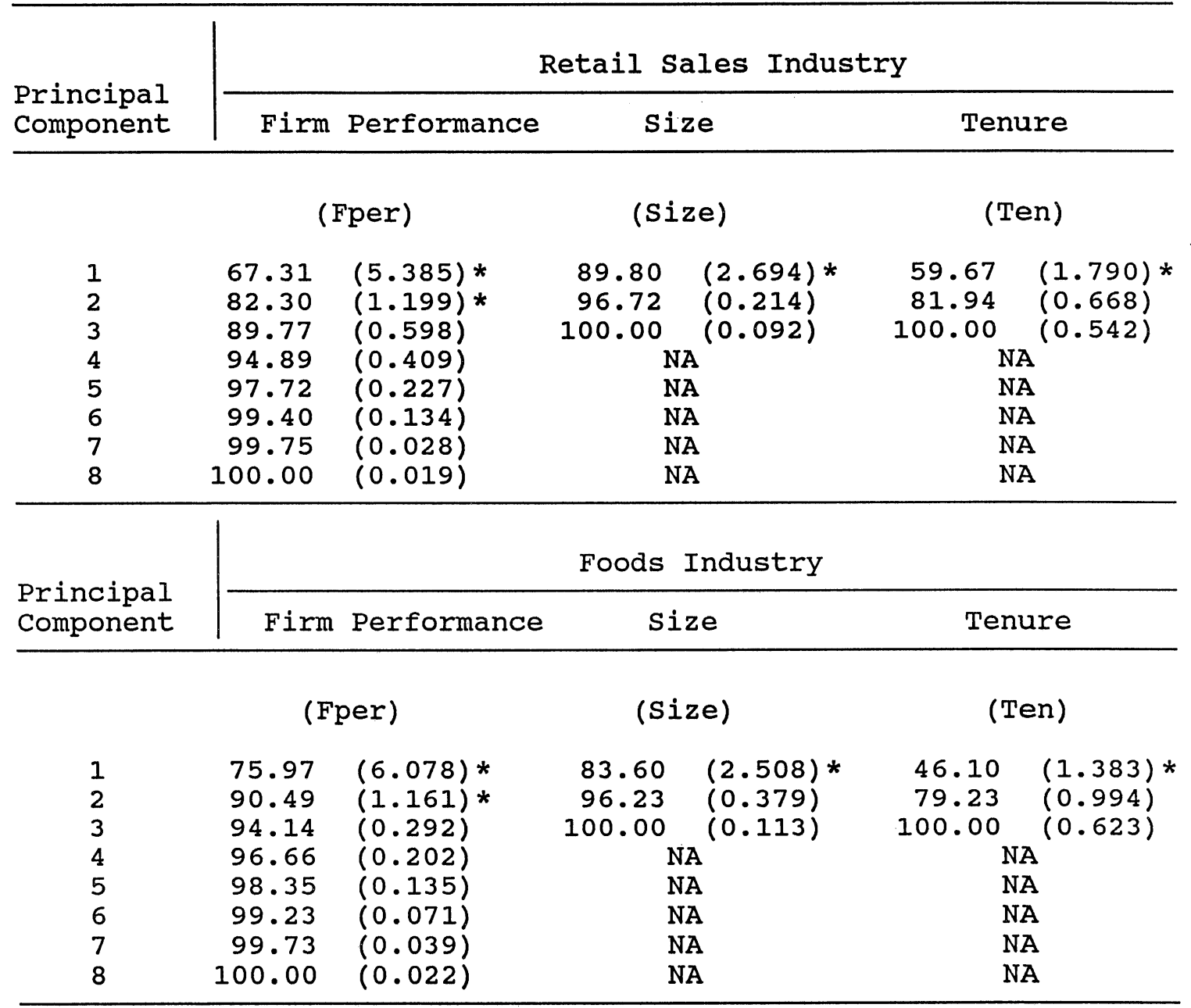

(Eigenvalues are given in parentheses)

* Principal Components used in regression analysis

$\mathrm{NA}$ : Not Applicable

Table 2: Retail Sales Industry Regression Results ( $n=34)$

\begin{tabular}{|c|c|c|c|c|}
\hline $\begin{array}{c}\text { Independent } \\
\text { Variables }\end{array}$ & & $\begin{array}{l}\text { Parameter } \\
\text { Estimates }\end{array}$ & $\begin{array}{c}t \\
\text { value }\end{array}$ & \\
\hline $\begin{array}{l}\text { Intercept } \\
\text { Fper (1st Principal } \\
\text { Fper (2nd Principal } \\
\text { Size (1st Principal } \\
\text { Ten (1st Principal }\end{array}$ & $\begin{array}{l}\text { Component) } \\
\text { Component) } \\
\text { Component) } \\
\text { Component) }\end{array}$ & $\begin{array}{r}724,653 \cdot 40 \\
63,171 \cdot 14 \\
-30,601 \cdot 28 \\
121,766.64 \\
60,552.56\end{array}$ & $\begin{array}{r}21.28 \\
1.86 \\
-0.90 \\
3.47 \\
1.64\end{array}$ & $\begin{array}{l}\frac{1}{2 /} \\
\frac{1}{3}\end{array}$ \\
\hline $\begin{array}{l}\text {-value } 4.25 \text { I/ } \\
\text { R-square } 0.44 \\
1 / \text { significant at the } \\
\text { 2/ significant at the } \\
\text { 3/ significant at the }\end{array}$ & $\begin{array}{l}1 \% \text { level } \\
5 \% \text { level } \\
10 \% \text { level }\end{array}$ & & & \\
\hline
\end{tabular}


The Journal of Applied Business Research - Vol. 6, No. 1

Table 3: Foods Industry Regression Results ( $\mathrm{n}=21)$

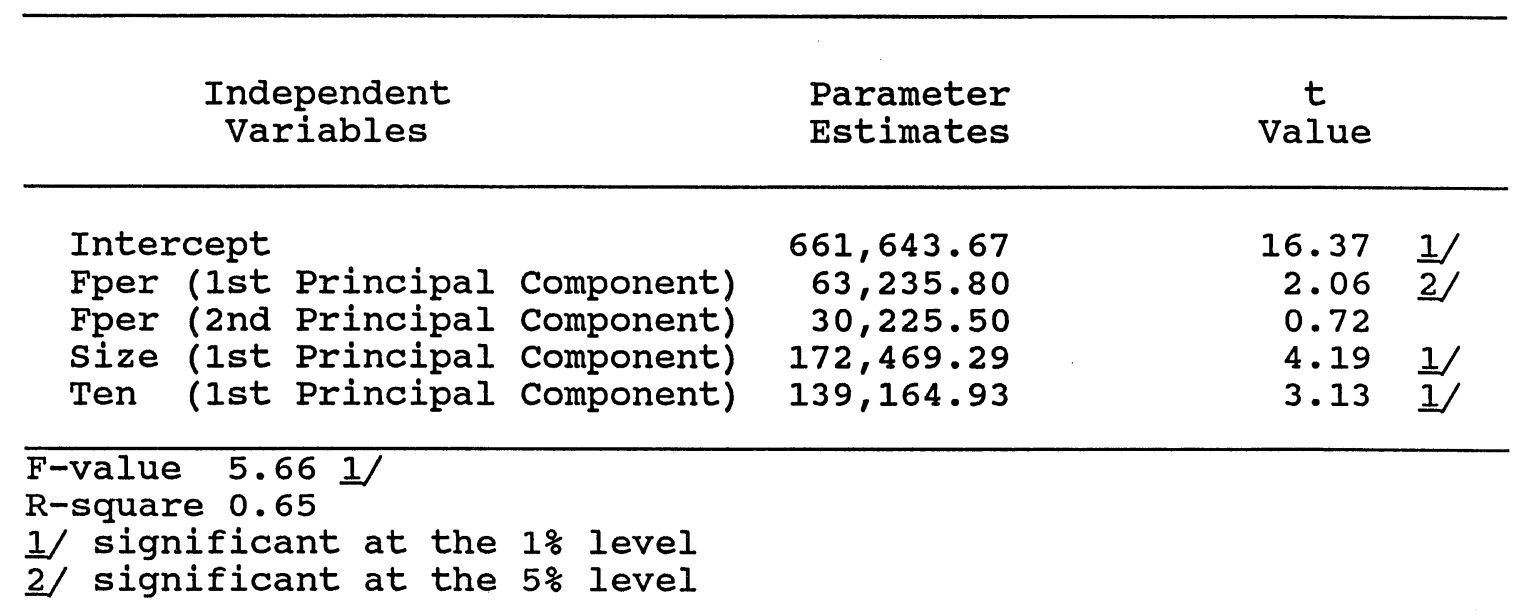

tionship exists between compensation and the firm performance and size indices. However, a priori, it was unclear whether greater "tenure" would lead to greater or lesser pay. Generally, one might postulate that as tenure increases so would compensation, but this assertion may be overshadowed by mobile executives with less tenure.

The results suggest that performance, size, and tenure have a positive impact on CEO compensation. The significance level of each variable is shown in tables 2 and 3, where it can also be seen that the overall model is significant at the $1 \%$ level for both industries. The coefficients of determination for the retail sales and the foods industries are $44 \%$ and $65 \%$ respectively suggesting that the model captures an adequate amount of variation in compensation.

The relationship between firm performance (the first principal component) and compensation is significant at the $5 \%$ level for both industries which shows that firm performance is an important indicator of CEO compensation and lends support to Lewellen and Huntsman's (1970) and Masson's (1971) arguments. Firm size is significant at the $1 \%$ level for both industries and the significance of this component stresses the importance of size on compensation and provides support for Baumol's (1967) assertions.

The tenure index indicates that background characteristics of CEOs seem to be more important in the foods industry than in the retail sales industry. This variable is significant at the $1 \%$ level in the foods industry and the $10 \%$ level for the retail sales industry. Reasons for the differences between the two industries are unclear. However, it may be due to the fact that the CEOs in the retail sales industry have, on average, been associated with their respective firms longer and been chief executive officers for more years than their counterparts in the foods industry (6). This argument lends support to Crystal's (1978) assertion that compensation increases more rapidly as executives move from one job to another than it does if the executive stays in the same position; i.e., the executive that is mobile can employ the market forces of supply and demand to his or her advantage more than the executive that is complacent or less mobile.

\section{Results: Pooling of the Industries}

Having adjusted each industry data set for heterscedasticity, a Chow test was employed to determine the equality between the coefficients for the two industries. The test results suggest the coefficients were not statistically different, therefore, the two data sets could be pooled and a single regression equation estimated. The results of the combined industry estimation are given in table 4 and show fundamentally the same results as those presented earlier, where each index had a positive impact on CEO compensation. These results show a high level of statistical significance and support the same arguments discussed earlier.

In this instance, the perceived differences encountered when analyzing the two industries 
The Journal of Applied Business Research - Vol. 6, No. 1

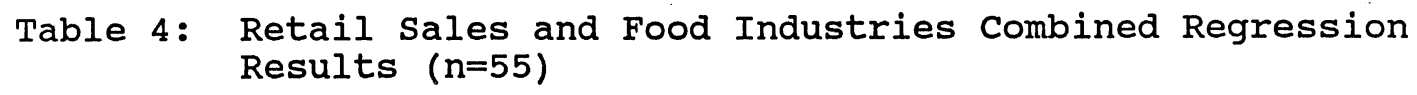

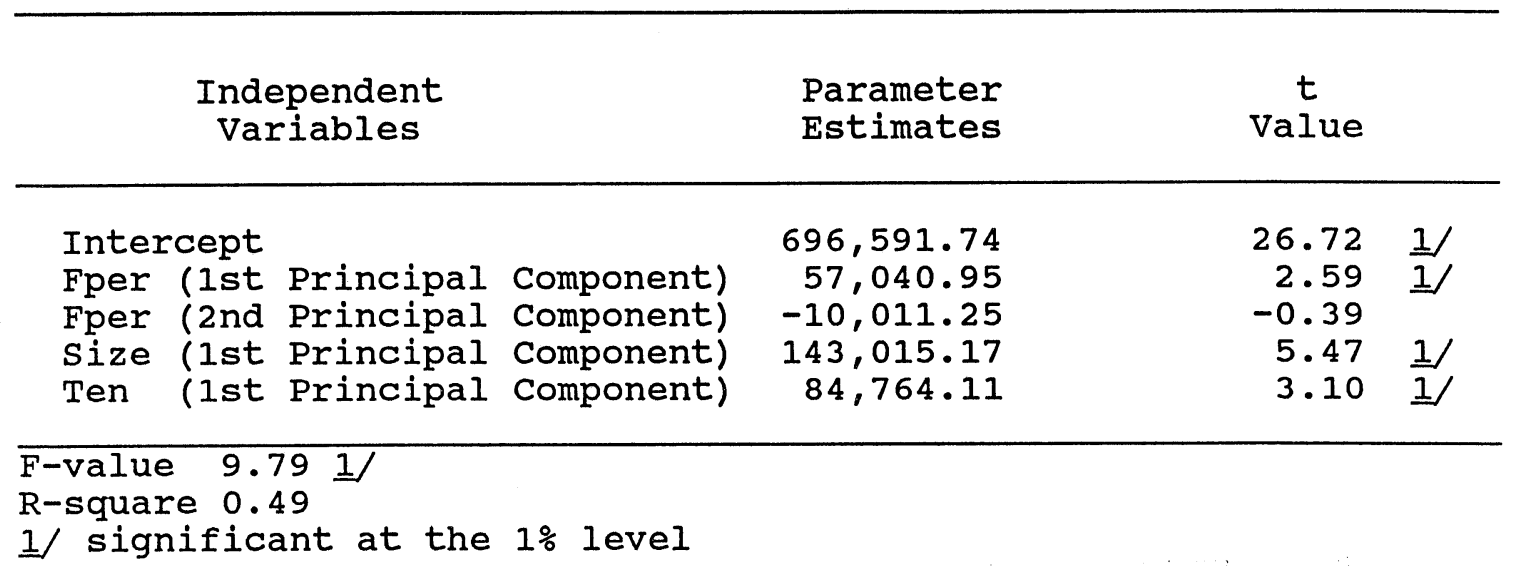

separately were obviously: not large enough to negate combining these specific data sets. However, the ability to combine data sets of various industries does not necessarily generalize from the results in this paper and should be examined (a Chow test) on a case by case basis.

\section{Summary and Conclusions}

Previous research has toiled with the problem of specifying firm characteristics that influence CEO compensation. The tendency has been to simplify the problem by analyzing variations in compensation as a function of only one or two narrowly defined firm characteristics. This study broadened that approach by employing indices as explanatory variables which are themselves linear combinations of several correlated variables.

It appears, in this study, that CEO compensation depends on both firm performance, as suggested by Lewellen and Huntsman, and firm siz$\mathrm{e}$, as suggested by Baumol. Additionally, there is evidence to support conclusions drawn by Hogan and McPheters as to the importance of background characteristics of CEOs.

By expanding the number of variables included in each of the various firm characteristics and then employing principal component analysis to pick up the major portion of the variation in the variables, the apparent contradiction between performance and size has been overcome. That is, both work significantly in setting compensation levels of CEOs, as well as do background characteristics.

The study also demonstrated that the combin- ing of industries to analyze CEO compensation is possible. However, caution should be used in generalizing the results from the two industries used in this paper.

The authors are grateful to the Georgia College Foundation for financial support and to two anonymous Journal reviewers for their comments.)

\section{Footnotes}

1 See Dhrymes (1970) or Maddala (1977) for a discussion of the principal component analysis technique.

2 A correlation analysis was performed on the variables included in each of the various indices and a test of significance confirmed our suspicions that the variables were significantly correlated.

3 One exception was an article by Agarwal (1981) which focused on a sample from the insurance industry.

4 Firm accounting data for this study were obtained from the "Fortune Directory of the Fifty Largest Commercial-Banking Companies, Life Insurance Companies, Diversified-Financial Companies, Retailing Companies, Transportation Companies and Utilities," Fortune, June, 1985 and 1986; and the "Fortune Directory of the Largest U.S. Industrial Corporations," Fortune, April, 1985 and 1986. Data from the retail sales industry consisted of 34 firms from the top 50 as ranked by sales in 1985; data from the foods industry consisted of 21 firms from the top 56 as ranked by sales in 1985 . Firms were eliminated from the data sets if they were wholly owned subsidiaries, cooperatives, if an extraordinary gain of more than 10 percent was reported for 1984 or 1985 , or if the CEO was the founder of the company. In addition, unavailable compensation data on 11 CEOs in the foods industry limited this dataset.

5 Compensation data of CEOs from each of the selected firms in both industries were obtained from Forbes, June 2, 1986.

6 Retail sales industry: tenure with firm, tenure as CEO, and age-mean years $=27,8,56$ respectively. Foods industry: tenure with firm, tenure as CEO, and age--mean years $=24,6,58$ respectively.

\section{References}

1 Agarwal, Naresh C. "Determinants of Executive Compensation," Industrial Relations, Vol. 20, No. 1 (Winter, 1981): 36- 
46.

2 Baker, Samuel H. "Executive Motivation and the Determinants of Managerial Compensation: A New Approach," Industrial Organization Review, Vol. 6, No. 2 (1978): 106-109.

3 Baumol, William J. Business Behavior, Value, and Growth, Harcourt, Brace, and World, Inc., New York, revised edition, 1967, p. 46.

4 "Bulls, Bears, and Bureaucrats--Major Forces Shaping Executive Compensation," Financial Executive, Vol. 441, No. 5 (May, 1983): 23-30.

5 Ciscel, David H. "Determinants of Executive Compensation," Southern Economic Journal, Vol. 40, No.4 (April, 1974): 613617.

6 Ciscel, David H. and Thomas M. Carroll. "The Determinants of Executive Salaries: An Economic Survey," Review of Economics and Statistics, Vol. 62, No. 1 (February, 1980): 7-13.

7 "Compensation," Journal of Accountancy, Vol. 162, No. 5 (November, 1986): 80-90.

8 Crystal, Graef S. "Executive Pay," Wall Street Journal, (March $6,1978)$.

9 Dhrymes, Phoebus J. Econometrics: Statistical Foundations and Applications, Harper \& Row Publishers, New York, 1970, Chapter 2: 53-65.

10 Dunlevey, James A. "Econometric Issues in the Analysis of Executive Compensation: A Comment," Review of Economics and Statistics, Vol. 67 (February, 1985): 171-174.

11 "Executive Compensation: Performance-Based Bonus Payments are on the Rise for Financial Executives," Financial Executive, Vol. 2 (October, 1986): 30-35.

12 Galbraith, John Kenneth. The New Industrial State, revised edition, New York: Houghton Mifflin, 1971.

13 Hogan, Timothy D. and Lee R. McPheters. "Executive Compensation: Performance versus Personal Characteristics," Southern Economic Journal, Vol. 46, No. 4 (April, 1980): 1060-1068.

14 Kim, Jae-on and Charles W. Mueller. Factor Analysis, Statistical Methods and Practical Issues, Series: Quantitative Applications in the Social Sciences, Sage Publications, Beverly Hills, California, 11th printing, 1978, Chapter 4, p. 43.

15 Lewellen, Wilbur G, and Blaine Huntsman. "Managerial Pay and Corporate Performance," American Economic Review, Vol. 60, No. 4 (September, 1970): 710-719.

16 Lewellen, Wilbur G. "Management and Ownership in the Large Firm," Journal of Finance, (May, 1969): 299-322.

17 Maddala, G.S. Econometrics, McGraw-Hill Book Company, New York, 1977, Chapter 10: 193-194.

18 Masson, Robert Tempest. "Executive Motivations, Earnings, and Consequent Equity Performance," Journal of Political Economy, Vol. 79 (1971): 1278-1292.

19 McGuire, Joseph W., John S.Y. Chin, and Albar O. Elbing. "Executive Incomes, Sales, and Profits," American Economic Review, Vol. 52 (September, 1962): 753-761.

20 "New Targeting for Executive Pay," Fortune, (May 4, 1981): 176-184.

21 Roberts, David R. "A General Theory of Executive Compensation Based on Statistically Tested Propositions," Quarterly Journal of Economics, LXX (May, 1956): 270-294. 